\title{
Synthesis of nanostructured solid-state phases of V7O16 and V2O5 compounds for ppb-level detection of ammonia
}

J. Huotari, J. Lappalainen, Jens Eriksson, Robert Bjorklund, E. Heinonen, I. Miinalainen, J.

Puustinen and Anita Lloyd Spetz

\section{Linköping University Post Print}

\section{Tweet}

N.B.: When citing this work, cite the original article.

Original Publication:

J. Huotari, J. Lappalainen, Jens Eriksson, Robert Bjorklund, E. Heinonen, I. Miinalainen, J. Puustinen and Anita Lloyd Spetz, Synthesis of nanostructured solid-state phases of V7O16 and V2O5 compounds for ppb-level detection of ammonia, 2016, Journal of Alloys and Compounds, (675), 433-440.

http://dx.doi.org/10.1016/j.jallcom.2016.03.116

Copyright: Elsevier

http://www.elsevier.com/

Postprint available at: Linköping University Electronic Press

http://urn.kb.se/resolve?urn=urn:nbn:se:liu:diva-127542 


\title{
Synthesis of Nanostructured Solid-State Phases of $\mathrm{V}_{7} \mathrm{O}_{16}$ and $\mathrm{V}_{2} \mathrm{O}_{5}$ Compounds for ppb-Level Detection of Ammonia
}

\author{
J. Huotari ${ }^{\mathbf{a}^{*}}$, J. Lappalainen ${ }^{\mathbf{a}}$, J. Eriksson ${ }^{\mathrm{b}}$, R. Bjorklund ${ }^{\mathbf{b}}$, E. Heinonen ${ }^{\mathrm{c}}$, I. Miinalainen ${ }^{\mathbf{d}}$, \\ J. Puustinen ${ }^{\mathbf{a}}$, and A. Lloyd Spetz ${ }^{\mathbf{a}, \mathbf{b}}$ \\ ${ }^{\mathrm{a}}$ Faculty of Information Technology and Electrical Engineering, P.O. Box 4500, \\ FIN-90014, University of Oulu, Finland \\ ${ }^{\mathbf{b}}$ Department of Physics, Chemistry and Biology, Linköping University, \\ SE-581 83, Linköping, Sweden \\ ${ }^{\mathrm{c}}$ Center of Microscopy and Nanotechnology, Erkki Koiso-Kanttilankatu 3, \\ Tietotalo 1, Linnanmaa, FIN-90570, Oulu \\ ${ }^{\mathrm{d}}$ Biocenter Oulu, P.O. Box 5000, FI-90014 University of Oulu, Finland \\ * Corresponding author: joni.huotari@ee.oulu.fi, tel: +358294487968
}

\begin{abstract}
Solid state phase of $\mathrm{V}_{7} \mathrm{O}_{16}$ with separate $\mathrm{V}_{2} \mathrm{O}_{5}$ phase were fabricated by pulsed laser deposition. The crystal structure and symmetry of the deposited films were studied with X-ray diffraction and Raman spectroscopy, respectively. Rietveld analysis was performed to the X-ray diffraction measurement results. The surface potentials and morphologies of the films were studied with atomic force microscopy, and microstructure of the thin films was analyzed by transmission electron microscopy. Raman spectroscopy and Rietveld refinement results confirmed that the thin-film crystal structures varied between orthorombic $\mathrm{V}_{2} \mathrm{O}_{5}$ phase and another phase, triclinic $\mathrm{V}_{7} \mathrm{O}_{16}$, previously found only in the walls of vanadium oxide nanotubes $\left(\mathrm{VO}_{\mathrm{x}}-\mathrm{NT}\right)$, bound together with organic amine. We have earlier presented the first results of stable and pure metal-oxide solid-state phase of $\mathrm{V}_{7} \mathrm{O}_{16}$ manufactured from ceramic $\mathrm{V}_{2} \mathrm{O}_{5}$ target. Here we show more detailed study of these structures. The microstructure studies showed a variation on the porosity of the films according to crystal structures and also some fiber-like nanostructures were found in the films. The surface morphology depended strongly on the crystal structure and the surface potential studies showed $50 \mathrm{meV}$ difference in the work function values between the phases. Compounds were found to be extremely sensitive towards ammonia, $\mathrm{NH}_{3}$, down to $\sim 40 \mathrm{ppb}$ concentrations, and have shown to
\end{abstract}


have the stability and selectivity to control the Selective Catalytic Reduction process, where nitrogen oxides are reduced by ammonia in, e.g. diesel exhausts.

Keywords: Vanadium oxides; Mixed phase; $\mathrm{V}_{7} \mathrm{O}_{16} ; \mathrm{V}_{2} \mathrm{O}_{5}$; Thin film

\section{Introduction}

Vanadium oxides have gained a constantly growing interest because of their varying material properties according to oxidation state. The material can have oxidation states between $\mathrm{V}^{2+}$ and $\mathrm{V}^{5+}$, the most famous compounds being vanadium pentoxide, $\mathrm{V}_{2} \mathrm{O}_{5}$ and vanadium dioxide, $\mathrm{VO}_{2}$. For example, vanadium dioxide has an interesting metal-insulator-transition (MIT) effect where it changes its phase structure from low-temperature insulating state to high-temperature metallic state at around $68^{\circ} \mathrm{C}$. This property has been studied in the context of, e.g. electrical and optical switches [1]. On the other hand, vanadium pentoxide $\mathrm{V}_{2} \mathrm{O}_{5}$ has been studied for chemical sensing purposes [2] and as a material for catalytic reactions [3]. Lately, a growing interest has been shown to fabrication of vanadium oxide nanotubes, often labelled as $\mathrm{VO}_{\mathrm{x}}-\mathrm{NT}$ or VONT, by chemical methods [4]. The structure of the tubes is composed of triclinic $\mathrm{V}_{7} \mathrm{O}_{16}$ layer walls with an organic amine in between the layers $[5,6]$. $\mathrm{VO}_{\mathrm{x}}-\mathrm{NTs}$ have been studied, e.g. as chemical sensing material and $\mathrm{Li}^{+}$battery applications $[7,8]$.

Vanadium oxides as a material group are relatively complex. They are often formed as a layered structure, e.g. the well-known vanadium pentoxide $\mathrm{V}_{2} \mathrm{O}_{5}$ [9] and can also exist in a more complex mixed-valence vanadium oxide form. The mixed valency occurs when oxygen vacancy defects are introduced to an ideal vanadium oxide structure. When the number of oxygen vacancies is above a certain limit, the vacancies couple and arrange along lattice planes and this is compensated by reorganization of V-O coordination units. This results in formation of related, more complex stoichiometries [10]. The often seen mixed valence oxides consisting of, e.g. both $\mathrm{V}^{4+}$ and $\mathrm{V}^{5+}$ ions have a crucial impact on the material properties. In our previous study, it was shown that when a thin film consists of both pure $\mathrm{V}_{2} \mathrm{O}_{5}$ phase, including only $\mathrm{V}^{5+}$ ions, and a mixed valency phase of 
$\mathrm{V}_{7} \mathrm{O}_{16}$, including both $\mathrm{V}^{4+}$ ions and $\mathrm{V}^{5+}$ ions, a dramatic effect on the electrical conductivity of the thin films occurs, causing both n-type and p-type conductivity, respectively, to exist in the same samples [11]. Twin-plane crystal structure is another property present, for instance in vanadium oxide single crystals and $\mathrm{VO}_{\mathrm{x}}-\mathrm{NT}$ 's, where the crystals are mirrored to each other with respect to a certain twin plane $[12,13]$. For example, in $\mathrm{V}_{7} \mathrm{O}_{16}$ phase, the crystals are rotational twins in the $a b$ plane, i.e. basal plane, of the unit cell [5]. These types of properties make vanadium oxides a very fascinating material group with possibilities to be utilized in many different kinds of applications.

Pulsed laser deposition (PLD) has been used to manufacture vanadium oxide thin films for some time [14], and it has some advantages to other methods including good repetition of stoichiometry of the target material in the films on the substrate and easy controlling the chemical composition of the films. We have previously shown the existence of a stable and pure metal oxide solid-state phase of $\mathrm{V}_{7} \mathrm{O}_{16}$ in a thin film structure. In this study, a comprehensive structural characterization of pulsed laser deposited nanostructured mixed phase $\mathrm{V}_{2} \mathrm{O}_{5}$ and $\mathrm{V}_{7} \mathrm{O}_{16}$ thin films was performed. It must be pointed out here, that pure vanadium pentoxide $\mathrm{V}_{2} \mathrm{O}_{5}$ films can be easily fabricated by PLD [15]. The most important result in this paper is the fabrication of pure stable solid-state phase of triclinic $\mathrm{V}_{7} \mathrm{O}_{16}$, even though as a mixture with $\mathrm{V}_{2} \mathrm{O}_{5}$, and the observation of extremely low detection limit of the compound towards ammonia gas. Also, the compositions have been proven to be very stable and selective as ammonia gas sensors in Selective Catalytic Reduction (SCR) process [16], when compared to $20 \mathrm{ppm}$ of $\mathrm{NO}$ and $50 \mathrm{ppm}$ of $\mathrm{CO}$.

\section{Experimental}

Excimer laser operating at a wavelength of $308 \mathrm{~nm}$ (Lambda Physik Compex 201) was used to deposit vanadium oxide thin films on $c$-cut $\mathrm{Al}_{2} \mathrm{O}_{3}$ (0001) and oxidized silicon substrates with a pulse repetition rate of $5 \mathrm{~Hz}$. Pure ceramic $\mathrm{V}_{2} \mathrm{O}_{5}$ disc was used as rotating target and the laser pulse energy densities used in depositions were $I=1.3 \mathrm{~J} / \mathrm{cm}^{2}$ and $\mathrm{I}=2.6 \mathrm{~J} / \mathrm{cm}^{2}$. The substrate temperatures of in-situ PLD processes were $\mathrm{T}=400{ }^{\circ} \mathrm{C}$ and $500{ }^{\circ} \mathrm{C}$. The deposition chamber was 
first evacuated to a base pressure of $\sim 5 \times 10^{-5}$ mbar and then oxygen partial pressure $\mathrm{p}\left(\mathrm{O}_{2}\right)=1 \times 10^{-2}$ mbar or $1.5 \times 10^{-2}$ mbar was added in the chamber. Some samples were post annealed at $400{ }^{\circ} \mathrm{C}$ for 1h in air atmosphere.

Crystal structure of the films was studied using $\theta-2 \theta$ and grazing incidence diffraction (GID) X-ray diffraction (XRD) by Bruker D8 Discover facility, and TOPAS software was used to make Rietveld refinement for the structure data. Vesta software was used in drawing the lattice models of the crystal structures [17]. HORIBA Jobin Yvon LabRAM HR800 Raman spectroscope with argonion laser with a wavelength of $488 \mathrm{~nm}$ was used to study the phonon modes of the samples. The surface potential and morphology were studied using Veeco Dimension 3100 atomic force microscope (AFM) and WSXM software [18]. Transmission electron microscopy (TEM) studies were made using Tecnai Spirit G2 electron microscope operated at $120 \mathrm{kV}$ and equipped with Quemesa CCD camera.

Platinum (Pt) electrodes with thickness of $400 \mathrm{~nm}$ together with $10 \mathrm{~nm}$-thick titanium (Ti) adhesion layers were fabricated to the surface of the thin films by DC magnetron sputtering. Then the sensors were glued on alumina based heating platform and Pt-100 temperature sensors were used to measure the temperature of the gas sensors. The resistance measurements were performed with a Keithley sourcemeter and Bronckhorst flow meters were used to control the gas pulses injected to the $1 \mathrm{~cm}^{3}$-sized gas measurement chamber. The carrier gas used was $20 \%$ of $\mathrm{O}_{2}$ in $\mathrm{N}_{2}$ and measurement temperature was $350{ }^{\circ} \mathrm{C}$. In all gas sensing measurements, the temperature was raised rapidly to $350{ }^{\circ} \mathrm{C}$ and then the sensors were kept at the temperature for several hours in order to clean the sensor and stabilize the resistance baseline. Before the injection of ppb-level of ammonia, $\mathrm{NH}_{3}$, to the chamber, the plastic gas tubes were replaced with new ones in order to prevent diffusion of buildup $\mathrm{NH}_{3}$ in the gas line to affect the adjusted concentration of ammonia gas in the chamber. 


\section{Results and discussion}

\subsection{Crystal structure characterization}

For exact determination of nanosized crystalline structure of the films, both Raman spectroscopy and X-ray diffraction methods were utilized. According to data shown in Fig. 1, all the films had two co-existing phases. The post annealed films, bottom curve, were composed of almost pure $\mathrm{V}_{2} \mathrm{O}_{5}$ phase [19]. Films deposited with parameters $\mathrm{I}=2.6 \mathrm{~J} / \mathrm{cm}^{2}, \mathrm{~T}=400{ }^{\circ} \mathrm{C}$ and $\mathrm{p}\left(\mathrm{O}_{2}\right)=1.5 \times 10^{-2} \mathrm{mbar}$, showed almost equal co-existence of $\mathrm{V}_{2} \mathrm{O}_{5}$ phase and another phase, as shown by middle curve in Fig.1. The other phase, identified by Raman modes at wavenumbers 167, 847, 882, 940 and 1034 $\mathrm{cm}^{-1}$, labelled by black circles in the top curve in Fig. 1, could be identified as a structure typically found in vanadium oxide nanotubes $\left(\mathrm{VO}_{\mathrm{x}}-\mathrm{NT}\right)$ [20,21]. On the other hand, films deposited with PLD-parameters $\mathrm{I}=2.6 \mathrm{~J} / \mathrm{cm}^{2}, \mathrm{~T}=500{ }^{\circ} \mathrm{C}$ and $\mathrm{p}\left(\mathrm{O}_{2}\right)=1.5 \times 10^{-2} \mathrm{mbar}$, were almost pure $\mathrm{VO}_{\mathrm{x}}-\mathrm{NT}$ phase films, as shown by the top curve in Fig. 1. In the literature, this $\mathrm{VO}_{\mathrm{x}}-\mathrm{NT}$ phase is always referred to triclinic $\mathrm{V}_{7} \mathrm{O}_{16}$ structure in multilayers separated by organic amine layers in $\mathrm{VO}_{\mathrm{x}}$ nanotubes [5,6]. Identical Raman spectra are here found in pure in organic solid-state metal oxide films. Also, it is worth noting that all the other Raman modes in Fig. 1 originate from orthorhombic Pmmn symmetry of $\mathrm{V}_{2} \mathrm{O}_{5}$. 


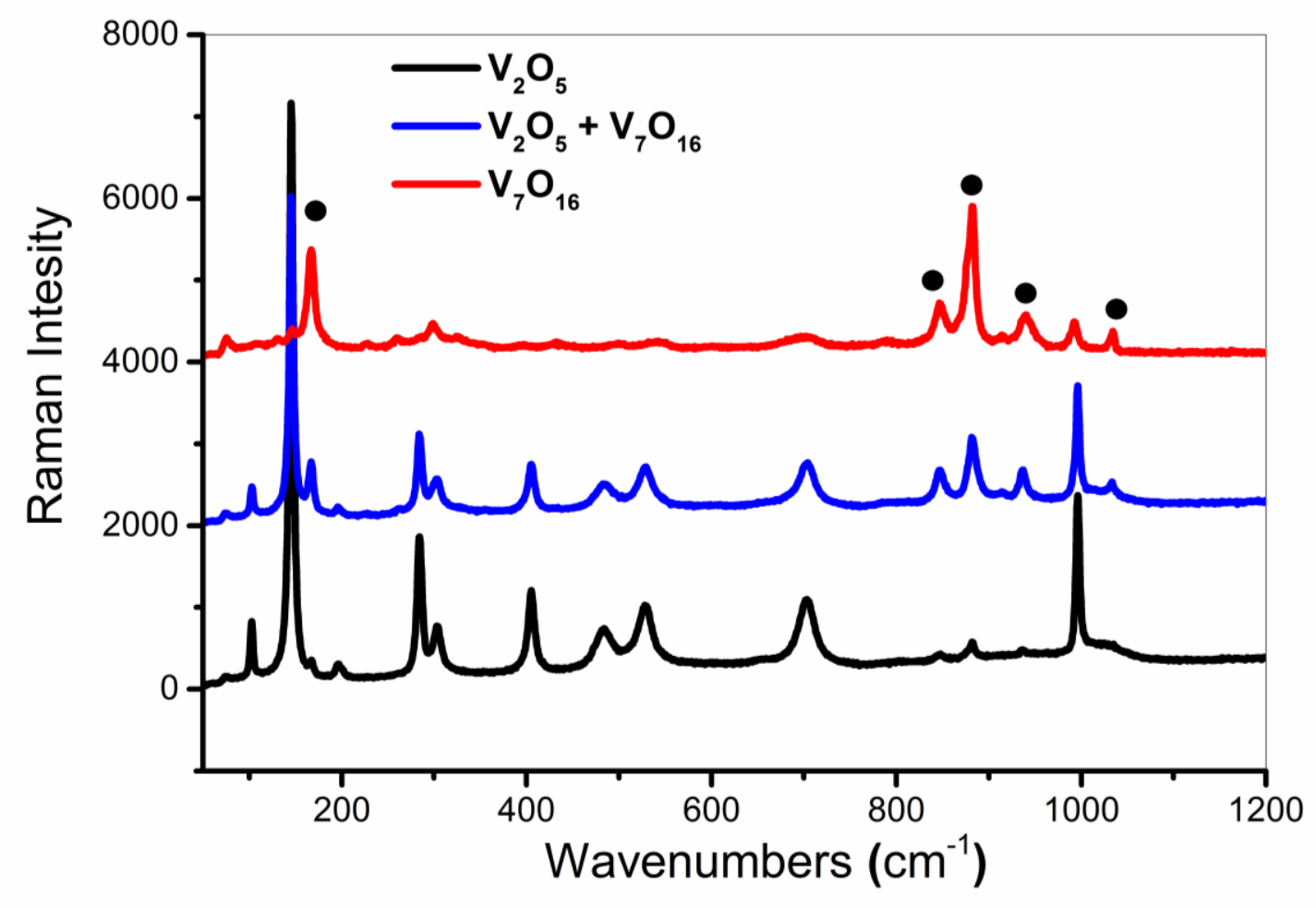

Figure 1. Raman spectra of the different vanadium oxide thin films. The black circles represent Raman modes typical to $\mathrm{VO}_{\mathrm{x}}$-NT-structure formed of layers of $\mathrm{V}_{7} \mathrm{O}_{16}$.

Rietveld refined $\theta-2 \theta$ X-ray diffraction data of a typical mixed $\mathrm{V}_{2} \mathrm{O}_{5}$ and $\mathrm{VO}_{\mathrm{x}}-\mathrm{NT}$-type phase thin film is shown in Fig. 2. Raman spectrum of such a film is shown by the middle curve in Fig. 1. The XRD data was fitted with both orthorhombic Pmmn symmetry in the case $\mathrm{V}_{2} \mathrm{O}_{5}$ [22] and triclinic $P-1$ symmetry in the case of $\mathrm{V}_{7} \mathrm{O}_{16}$ [5]. It is clearly observed from Fig. 2, that Rietveld refinement calculated curve fits all the measured XRD peaks, and relates reflections from $(003)_{\mathrm{T}} \ldots .(2,-1,2)_{\mathrm{T}}$ planes to triclinic $\mathrm{V}_{7} \mathrm{O}_{16}$ structure, and $(200)_{\mathrm{O}} \ldots . .(011)_{\mathrm{O}}$ planes to orthorhombic $\mathrm{V}_{2} \mathrm{O}_{5}$ structure, respectively. It is also worth mentioning that various phases of vanadium oxides, including $\mathrm{VO}_{2}, \mathrm{~V}_{2} \mathrm{O}_{3}$, and $\mathrm{V}_{4} \mathrm{O}_{9}$ structure, were also examined without any success in fitting. The $\mathrm{R}$ weighted parameter, measuring the relation of the observed and calculated intensities of the measurement, was RWP $=24.384 \%$. The closer to zero the RWP value is, the better the fit. The relatively high RWP value in this measurement is a result of a quite strong background noise. 
Another parameter also used to measure the reliability of the Rietveld refinement calculation is $\chi^{2}$ function, i.e. goodness-of-fit, value should be as close to 1 as possible [23]. The $\chi^{2}$ function measures the relation between the gained RWP value and the expected R-value based on the measurement data. In the fitting in Fig. 2 , the value of goodness-of-fit was $\chi^{2}=1.30$. Overall, these Rietveld refinement results together with Raman results confirm unambiguously that the thin films are indeed composed of both pure $\mathrm{V}_{2} \mathrm{O}_{5}$ and $\mathrm{V}_{7} \mathrm{O}_{16}$ phases.

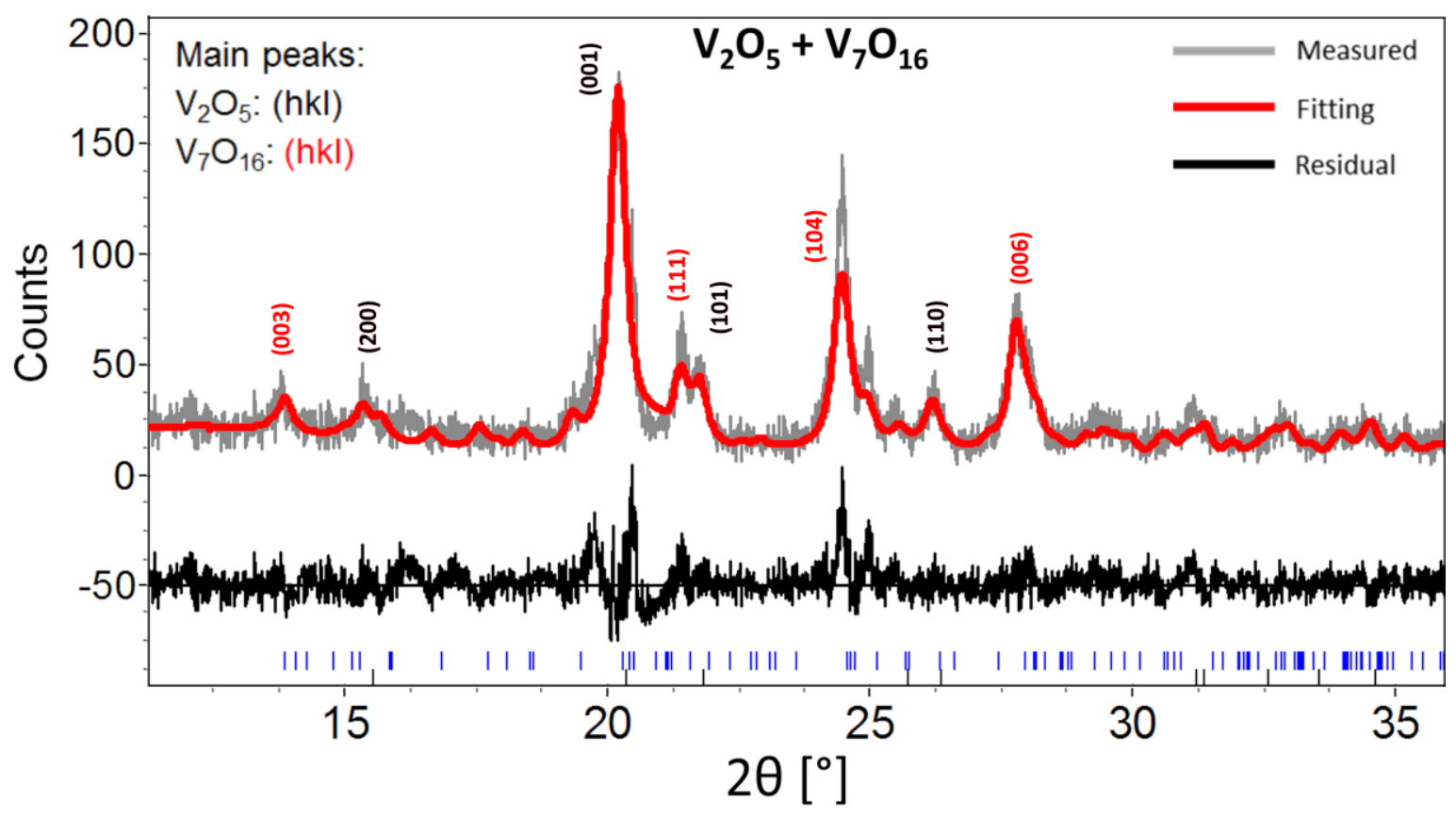

Figure 2. A typical $\theta-2 \theta$ X-ray diffraction pattern with Rietveld refinement calculated using structural parameters of orthorhombic $\mathrm{V}_{2} \mathrm{O}_{5}$ phase with symmetry (pmmn) and triclinic $\mathrm{V}_{7} \mathrm{O}_{16}$ phase with symmetry $(P-1)$.

The lattice models used in the refinement are shown in Fig. 3. The unit cell of orthorhombic Pmmn $\mathrm{V}_{2} \mathrm{O}_{5}$ is composed of $\mathrm{VO}_{6}$ octahedra structures linked from the edges by chained oxygen atoms (O3) and from the corners by bridging oxygen atoms (O1), as shown in Fig. 3 a). The unit cell of triclinic $P-1 \quad \mathrm{~V}_{7} \mathrm{O}_{16}$ is composed of two weakly bonded sheets of $\mathrm{VO}_{5}$ square pyramids combined via $\mathrm{VO}_{4}$ tetrahedra around vanadium (V5) atom, as shown in Fig. 3 b). This form of 
$\mathrm{V}_{7} \mathrm{O}_{16}$ structure has not been reported as a stable solid-state thin-film structure before. Typical layered structure of vanadium oxides is now also seen in the structure of triclinic $\mathrm{V}_{7} \mathrm{O}_{16}$ unit cell, as shown in Fig. 3 b). Due to asymmetric and weak bonding of vanadium (V5) atoms, vanadium oxides are borne to form twin-plane structures to compensate the charge in equilibrium. One twinplane is depicted in Fig. 3 b) by a blue dashed line. The channels formed by these planes are found to be responsible for high response, when material is used as a gas sensor [12]. This could be due to new bondings formed by $\mathrm{NH}_{3}$ molecules between the $\mathrm{V}_{7} \mathrm{O}_{16}$ sheets, in a similar way as the amines in $\mathrm{VO}_{\mathrm{x}}-\mathrm{NT}$ structures.

a)
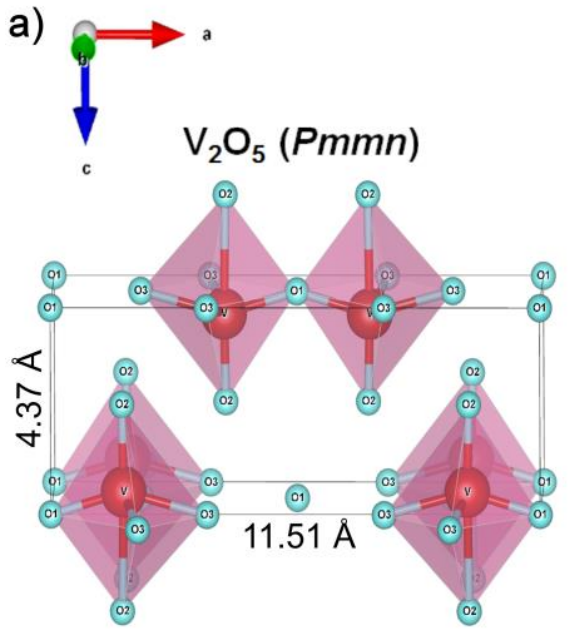

b)

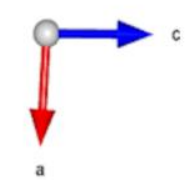

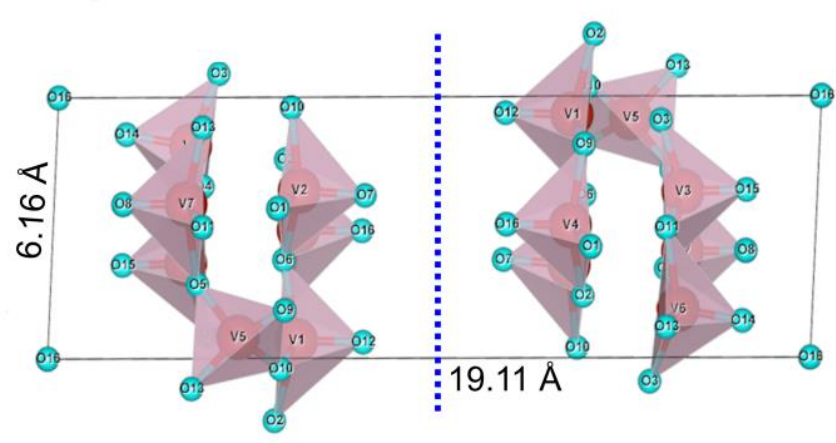

Figure 3. Lattice models used in Rietveld refinement calculations for vanadium oxide thin films: a) orthorhombic Pmmn $\mathrm{V}_{2} \mathrm{O}_{5}$ phase and b) triclinic $\mathrm{P}-1 \mathrm{~V}_{7} \mathrm{O}_{16}$ phase.

The grazing incidence diffraction (GID) X-ray diffraction patterns, Rietveld refinement fittings and the fitting residuals of the three different types of vanadium oxide thin-film structures are shown in Fig. 4. Fitting results clearly show the existence of both orthorombic $\mathrm{V}_{2} \mathrm{O}_{5}$ and triclinic $\mathrm{V}_{7} \mathrm{O}_{16}$ phases in all thin films, only the dominance between the two phases varies in compositions of the different films. In Fig. 4 a), XRD data of the film with a dominating $\mathrm{V}_{2} \mathrm{O}_{5}$ phase mixed with a minor $\mathrm{V}_{7} \mathrm{O}_{16}$ phase is presented. Fig. 4 b) presents $\mathrm{XRD}$ data of the film with about equal presence of the two phases in the films composition. Finally, XRD data of the film with a dominating $\mathrm{V}_{7} \mathrm{O}_{16}$ 
phase is shown in Fig. 4 c). In Table 1, the main Rietveld refinement fitting parameters of one of the three vanadium oxide thin-film structures are presented together with reference parameters gained from the literature. All of the fittings were made within a fitting accuracy with RWP $=5.47 \%$ and $\chi^{2}=1.24$ in Fig. 4 a), RWP $=10.68 \%$ and $\chi^{2}=2.21$ in Fig. 4 b), and RWP $=11.58 \%$ and $\chi^{2}=1.22$ in Fig. 4 c).

The calculated Rietveld refinement results are in very good agreement with the measured data in the two thin-film structures presented in Figs. 4 a) and b). The measured XRD curves have high intensities and thus also the fitting could be done more accurately. However, the measured XRD result presented in Fig. 4 c) has a low intensity in the peaks present and also the background noise is higher than in the results in Figs. 4 a) and b). These properties make the Rietveld refinement calculations more challenging for the thin-film with majority $\mathrm{V}_{7} \mathrm{O}_{16}$ phase in the structure, and thus also the residual values are much higher. However, the lattice model of triclinic $\mathrm{V}_{7} \mathrm{O}_{16}$ fitted well to all of the measured XRD result, as can be seen from the main peaks in the curve, e.g. $2 \theta \sim 24.9^{\circ}$. Also, other common vanadium oxide phase structures were studied in the context of the XRD and Raman data analysis, e.g., $\mathrm{VO}_{2}, \mathrm{~V}_{6} \mathrm{O}_{13}, \mathrm{~V}_{2} \mathrm{O}_{3}$, and $\mathrm{V}_{4} \mathrm{O}_{9}$. However, when both the Raman and Rietveld refinement results are taken into account, these other phases did not fit to the gained measurement results. Thus, as a conclusion, it can be said that the results presented here point very strongly to the co-existence of both $\mathrm{V}_{2} \mathrm{O}_{5}$ and $\mathrm{V}_{7} \mathrm{O}_{16}$ phases in the thin-film structures. When fitted unit cell lattice constants are compared to bulk materials values found in the literature, as shown in Table 1, it is observed that lattice constants are typically shorter for the nanostructured films. This is most likely due to substrate interface or deposition process generated compressive residual stress in the films.

Generally, Rietveld refinement is also used to quantify the concentrations of different materials in, e.g. ceramic powders. However, with thin films, where there are so many different properties affecting the X-ray diffraction curve, for example strains between the substrate and thin film and orientation effects of the thin film, it is often more difficult and inaccurate to quantitatively 
calculate the phase composition of the film. As also in this particular case, Topas software uses every possible reflection of the crystal structures studied, which in this case are orthorhombic $\mathrm{V}_{2} \mathrm{O}_{5}$ and triclinic $\mathrm{V}_{7} \mathrm{O}_{16}$, in the quantitative phase composition calculation. Obviously, the triclinic vanadium oxide phase has a much larger number of reflections in the $2 \theta$-angle region studied than the orthorhombic phase, which can lead to situation in which the amount of $\mathrm{V}_{7} \mathrm{O}_{16}$ phase is over estimated in the quantitative analysis. However, this problem can be minimized by taking care that only the (hkl) reflections found in the measured XRD data are included in the Rietveld calculations for each detected phase, and the effect of noise is carefully diminished (data presented in Fig. 4 c). After such quantitative Rietveld calculations, results are quite well in concurrence with the Raman measurement data presented previously. For the major $\mathrm{V}_{2} \mathrm{O}_{5}$ film, the quantitative result was $67 \%$ of $\mathrm{V}_{2} \mathrm{O}_{5}$ phase and $33 \%$ of $\mathrm{V}_{7} \mathrm{O}_{16}$, for the more equal mixture of the two phases according to Raman measurements, the result was $45 \%$ of $\mathrm{V}_{2} \mathrm{O}_{5}$ phase and $55 \%$ of $\mathrm{V}_{7} \mathrm{O}_{16}$, and for the film with major $\mathrm{V}_{7} \mathrm{O}_{16}$ phase $15 \%$ of $\mathrm{V}_{2} \mathrm{O}_{5}$ phase and $85 \%$ of $\mathrm{V}_{7} \mathrm{O}_{16}$. 

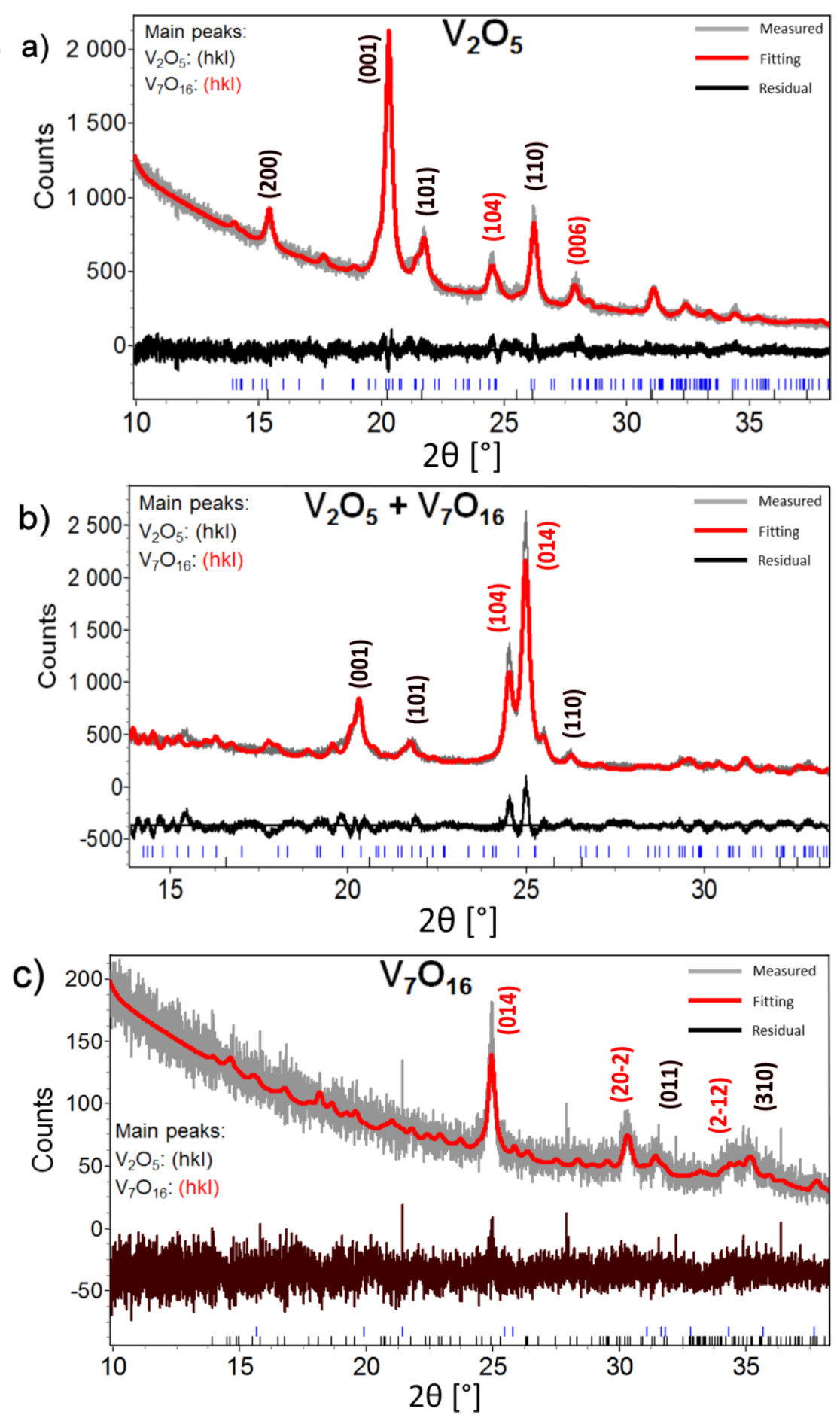

Figure 4. The measured GID XRD data with calculated Rietveld refinement results of the vanadium oxide thin films: a) film with a dominating orthorhombic $\mathrm{V}_{2} \mathrm{O}_{5}$ phase, b) film with equal mixture of orthorhombic $\mathrm{V}_{2} \mathrm{O}_{5}$ phase and triclinic $\mathrm{V}_{7} \mathrm{O}_{16}$ phase, and $\mathbf{c}$ ) film with dominating triclinic $\mathrm{V}_{7} \mathrm{O}_{16}$ phase. 


\begin{tabular}{|c|c|c|c|c|}
\hline $\begin{array}{c}\text { RWP }(\%)=5.47 \\
\chi^{2}=1.24\end{array}$ & $\mathrm{~V}_{7} \mathrm{O}_{16}$ & $\mathrm{~V}_{2} \mathrm{O}_{5}$ & $\mathrm{~V}_{7} \mathrm{O}_{16}[5]$ & $\overline{\mathrm{V}_{2} \mathrm{O}_{5}[24]}$ \\
\hline Spacegroup & $\mathrm{P}-1$ & Pmmn & $P-1$ & Pmmn \\
\hline \multicolumn{5}{|l|}{$\begin{array}{c}\text { Lattice } \\
\text { parameters }\end{array}$} \\
\hline$a(\dot{A})$ & 6.06 & 11.48 & 6.16 & 11.51 \\
\hline$b(\AA)$ & 6.12 & 3.56 & 6.17 & 3.56 \\
\hline$c(\AA)$ & 19.36 & 4.38 & 19.11 & 4.37 \\
\hline alpha $\left({ }^{\circ}\right)$ & 96.39 & 90 & 96.14 & 90 \\
\hline beta $\left({ }^{\circ}\right)$ & 92.87 & 90 & 92.82 & 90 \\
\hline $\operatorname{gamma}\left({ }^{\circ}\right)$ & 89.48 & 90 & 90.07 & 90 \\
\hline Cell Volume $\left(\AA^{3}\right)$ & 712.3 & 178.9 & 721.5 & 179.2 \\
\hline
\end{tabular}

Table 1. The main Rietveld refinement fitting parameters of one of the three vanadium oxide thinfilm structures with reference parameters from the literature.

\subsection{Microstructure of the thin films}

Cross-section microstructure studies were made by transmission electron microscopy (TEM). In Fig. 5 a), TEM micrograph of the thin film with dominating $\mathrm{V}_{2} \mathrm{O}_{5}$ phase is presented. The film shows a clear polycrystalline structure with only minor fiber or tubular-like structures. Also, the film seems to be very dense without any pores. TEM micrographs of the film with structure of both $\mathrm{V}_{2} \mathrm{O}_{5}$ and $\mathrm{V}_{7} \mathrm{O}_{16}$ phases are presented in Figs. 5 b) and c). Cross-section micrographs show a strong porosity in the thin film structure, and also the strong existence of clear fiber or tubular-like textured nanostructures. In Figs. 5 d) and e), TEM micrographs of the film with dominating $\mathrm{V}_{7} \mathrm{O}_{16}$ phase are presented. Cross-section micrographs show now again dense polycrystalline structure. The fiber or tubular-like nanostructures with multi-layered fine structure, as shown in Fig. 5e), are now very distinctive and strong in this film. This could be expected according the results from Raman spectroscopy and XRD measurements, assuming that the amount of triclinic $\mathrm{V}_{7} \mathrm{O}_{16}$ phase is comparable to the amount of fiber or tubular-like nanostructures in the film composition. With this 
assumption, the existence of these fine structures is another evidence of the presence of triclinic $\mathrm{V}_{7} \mathrm{O}_{16}$ phase in the thin films. However, it should be pointed out, that these structures differ from the conventional vanadium oxide nanotubes, $\mathrm{VO}_{\mathrm{x}}-\mathrm{NTs}$, because of the manufacturing method. In PLD process, as compared to chemical precipitation, there are no organic substances present in the growth process, only oxygen gas and a pure ceramic $\mathrm{V}_{2} \mathrm{O}_{5}$ target in vacuum conditions. Hence, it is clear that the fiber or tubular-like structures here are composed solely of $\mathrm{V}_{7} \mathrm{O}_{16}$ solid state phase. It has been suggested elsewhere [5], that the reason for the tubular-like morphology of $\mathrm{V}_{7} \mathrm{O}_{16}$ is reduction of $\mathrm{V}^{5+}$ ions to $\mathrm{V}^{4+}$ of the $\mathrm{VO}_{5}$ tetrahedra structure in the $\mathrm{V}_{7} \mathrm{O}_{16}$ crystal. Vanadium $\mathrm{V}^{4+}$ ions are much larger in size than $\mathrm{V}^{5+}$, and thus the size of one side of $\mathrm{V}_{7} \mathrm{O}_{16}$ layer will increase, causing the tendency to form tubular structures of the layers. As a conclusion from the microstructural studies made by TEM, it was observed that the films have much more porous structure when the two phases $\mathrm{V}_{2} \mathrm{O}_{5}$ and $\mathrm{V}_{7} \mathrm{O}_{16}$ are equally mixed in the same film when compared to the denser films with either $\mathrm{V}_{2} \mathrm{O}_{5}$ or $\mathrm{V}_{7} \mathrm{O}_{16}$ phase dominating the composition. Also, the existence of fiber or tubular-like nanostructures is largest in films with a strong presence of $\mathrm{V}_{7} \mathrm{O}_{16}$ phase.

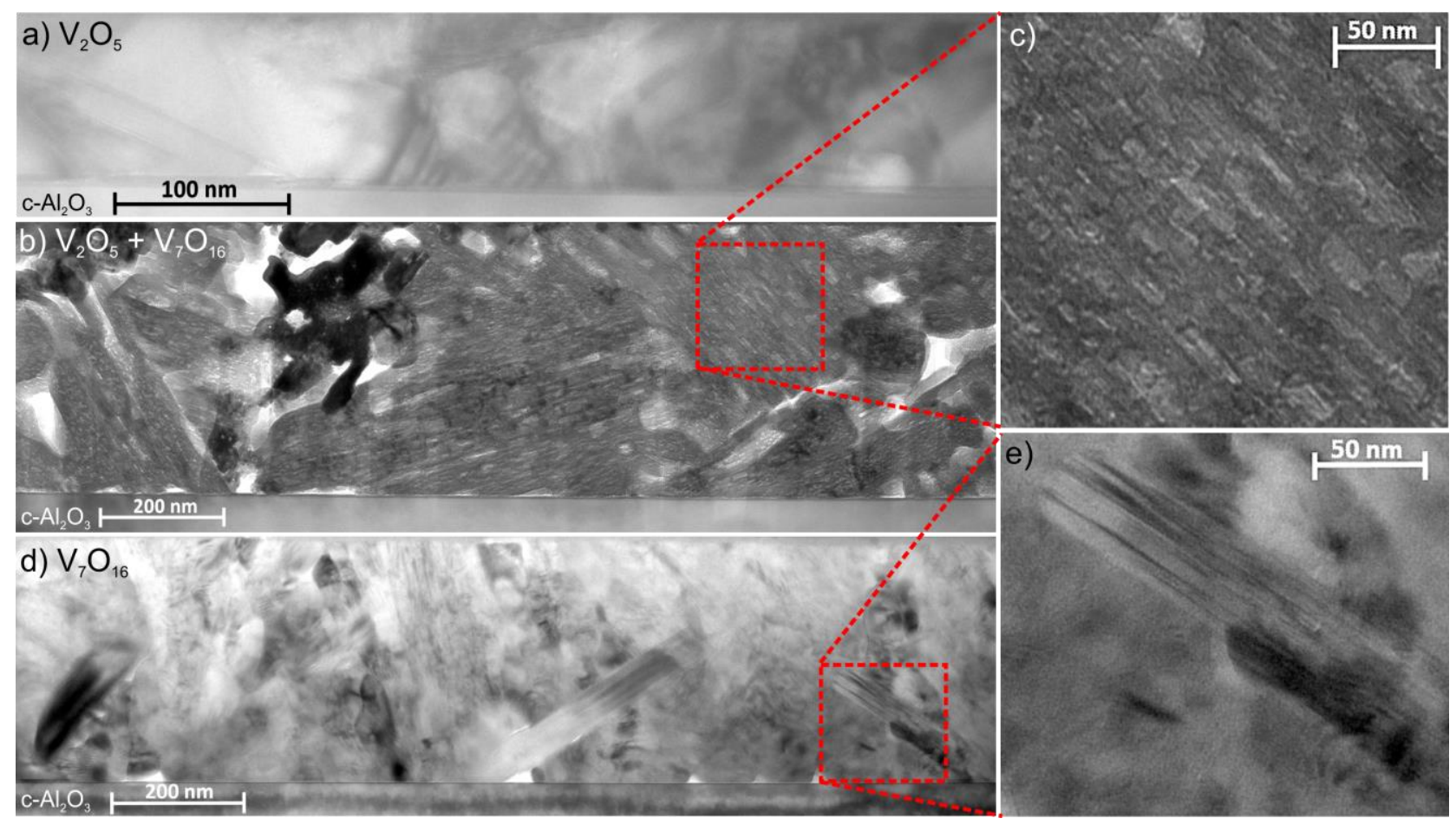


Figure 5. TEM cross-section images of a) film with a dominating orthorhombic $\mathrm{V}_{2} \mathrm{O}_{5}$ phase, b), c) film with equally strong orthorhombic $\mathrm{V}_{2} \mathrm{O}_{5}$ phase and triclinic $\mathrm{V}_{7} \mathrm{O}_{16}$ phase, and d), e) film with dominating triclinic $\mathrm{V}_{7} \mathrm{O}_{16}$ phase.

\subsection{Surface potential and morphology}

Atomic force microscopy (AFM) and Kelvin probe method were utilized to measure surface morphology and surface potential maps of the films with different compositions. The potential maps present the difference between the work functions of the platinum AFM tip and the thin film surface, i.e. $\Delta \Phi=\Phi_{\mathrm{Pt}}-\Phi_{\text {film }}$, and thus $\mathrm{mV}$ scale in the potential maps in Fig. 6 equals to meV scale of work function. The section graphs show the surface potential value along the red line drawn in surface potential maps. In all the thin film surfaces, the existence of particulate droplets produced in PLD process can be seen as bright white spots in morphology micrographs. In Fig 6 a), the morphology and potential graphs of the film with a dominating $\mathrm{V}_{2} \mathrm{O}_{5}$ phase are shown. The micrographs show a smooth film surface with rms roughness $\mathrm{R}_{\mathrm{q}} \approx 14.2 \mathrm{~nm}$. The surface potential map follows the variation of the surface height in the case of large variations like droplets, otherwise the potential map is quite smooth, with value of $\Delta \Phi \approx-150 \mathrm{meV}$. In Fig. $6 \mathrm{~b}$ ), the micrographs and data of the film with equal mixture of both $\mathrm{V}_{2} \mathrm{O}_{5}$ and $\mathrm{V}_{7} \mathrm{O}_{16}$ phases are presented. The surface is now rougher with rms roughness $\mathrm{R}_{\mathrm{q}} \approx 28.3 \mathrm{~nm}$. Also, the surface potential map shows the phase composition variations between $\mathrm{V}_{2} \mathrm{O}_{5}$ phase as darker areas and $\mathrm{V}_{7} \mathrm{O}_{16}$ phase as lighter areas, respectively. It is also obvious, that surface potential map is distinctively different from the surface morphology in Fig. 6 a), and thus do not follow the variation of sample surface height profile. This proves that there are two different phases with two different work functions existing in the thin-film surface. The morphology and potential maps of the film with dominating $\mathrm{V}_{7} \mathrm{O}_{16}$ phase are shown in Fig. $6 \mathrm{c}$ ). In this case, the surface is also quite smooth with $\mathrm{R}_{\mathrm{q}} \approx 14.6 \mathrm{~nm}$. The surface potential value follows the surface morphology in the same way as in the case of 
dominating $\mathrm{V}_{2} \mathrm{O}_{5}$ film in Fig. 6 a). However, average surface potential value $\Delta \Phi \approx-110 \mathrm{meV}$ differs from the film with a strong $\mathrm{V}_{2} \mathrm{O}_{5}$ phase by about $\approx 40 \mathrm{meV}$. This directly demonstrates the $\approx 40$ meV difference in work function values of the two films with dominating $\mathrm{V}_{2} \mathrm{O}_{5}$ and $\mathrm{V}_{7} \mathrm{O}_{16}$ phases, and thus also proves the different work functions of the two phases. It should be pointed out here, that as the orthorhombic $\mathrm{V}_{2} \mathrm{O}_{5}$ phase is proven to be $n$-type semiconductor, the triclinic $\mathrm{V}_{7} \mathrm{O}_{16}$ is shown to have $p$-type behaviour [25,7].

As a conclusion from the AFM surface morphology and potential data, it is shown that when the two phases $\mathrm{V}_{2} \mathrm{O}_{5}$ and $\mathrm{V}_{7} \mathrm{O}_{16}$ are equally mixed together to the same film composition, the surface gets much rougher and the film more porous, as compared to the smoother surfaces seen in the single phase films. Also, the surface potential measurements clearly proved the existence of two different separate phases in thin films by showing the two different work function values of the thin films with dominating $\mathrm{V}_{2} \mathrm{O}_{5}$ and $\mathrm{V}_{7} \mathrm{O}_{16}$ phases. 

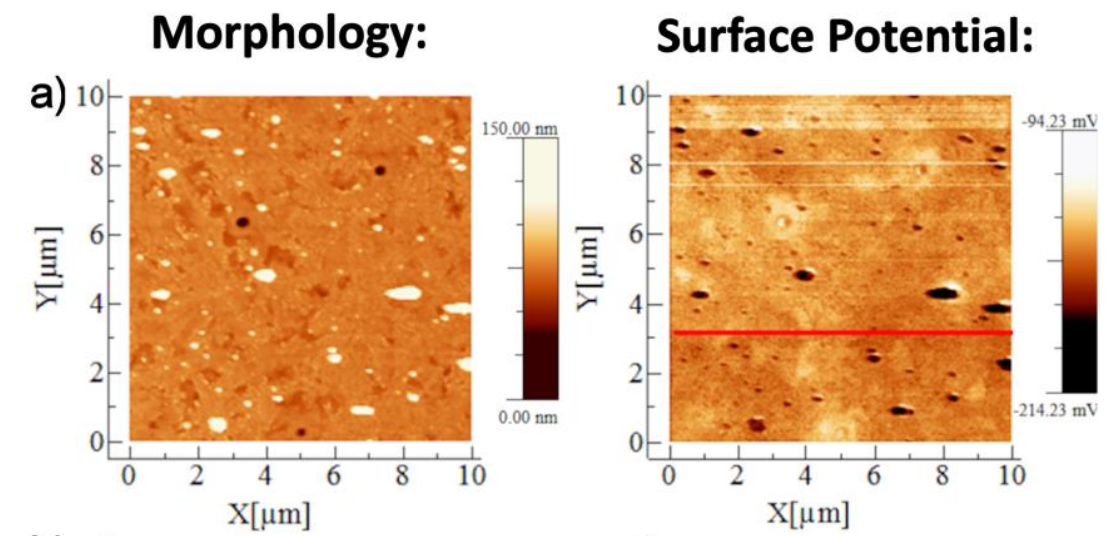

Section (Red Line):
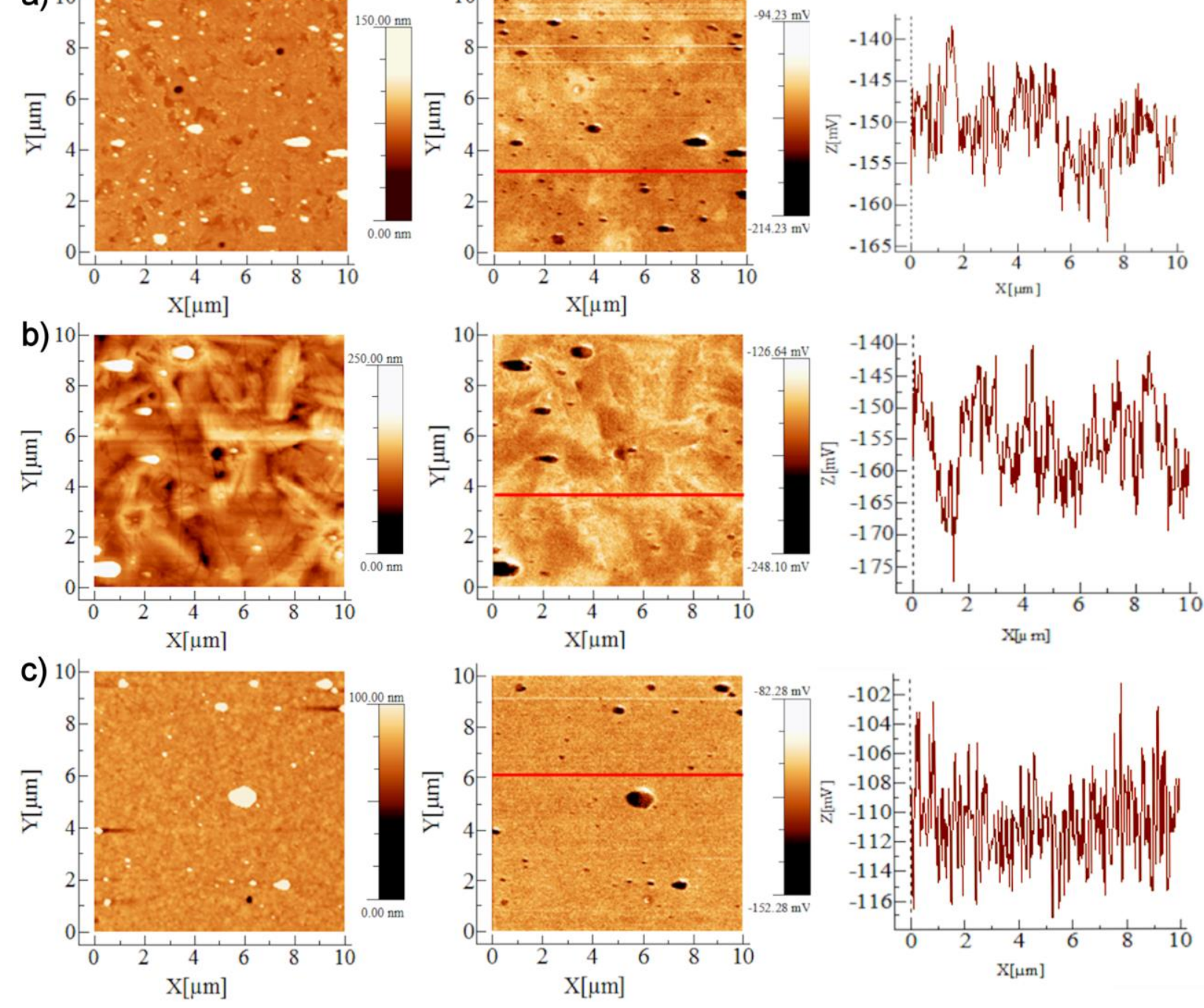

Figure 6. AFM surface morphology micrographs (left), surface potential maps (middle), and section graphs of the surface potential maps along the red lines of a) film with a dominating orthorhombic $\mathrm{V}_{2} \mathrm{O}_{5}$ phase, b) film with mixture of both orthorhombic $\mathrm{V}_{2} \mathrm{O}_{5}$ phase and triclinic $\mathrm{V}_{7} \mathrm{O}_{16}$ phase, and c) film with dominating triclinic $\mathrm{V}_{7} \mathrm{O}_{16}$ phase.

\subsection{Ammonia gas sensing properties}

The porous mixed phase thin-film structures with $\mathrm{V}_{2} \mathrm{O}_{5}$ and $\mathrm{V}_{7} \mathrm{O}_{16}$ were also deposited on oxidized silicon substrates to study their chemical sensing properties, especially towards ammonia $\mathrm{NH}_{3}$ gas. The films deposited on oxidized silicon were made intentionally thinner than the ones 
made for the structural characterization on sapphire substrates. Making the films thinner in this way is known to enhance their gas sensing properties. Also, a minor change in the morphology of the sensing layers was noticed when the substrate was changed, but the vanadium oxide phase composition could still be tuned in a similar way regardless of the substrate used. The change in the surface morphology of the films, reason for this being most probably the change of the substrate material, clearly enhanced the gas sensitivity of these layers. These observations have also been reported in our previous studies $[11,16]$. Thus it can be concluded, that the change of substrate material from $\mathrm{Al}_{2} \mathrm{O}_{3}$ to oxidized silicon, and varying the film thickness, has mainly effect on the surface morphology of films, but not on the crystalline structure or phase composition. This is due to accurately adjusted PLD conditions including in-situ heat treatment procedure and oxygen partial pressure $\mathrm{p}\left(\mathrm{O}_{2}\right)$.

Also, it was shown in our earlier studies $[11,16]$, that when the phase composition in the thin film is tailored to an optimum ratio between the $\mathrm{V}_{2} \mathrm{O}_{5}$ and $\mathrm{V}_{7} \mathrm{O}_{16}$ phases, the response to gases, especially to $\mathrm{NH}_{3}$, reaches its highest value. Also, the selectivity of such films towards ammonia was clearly improved, for example, in comparison to nitrogen oxides $\left(\mathrm{NO}_{\mathrm{x}}\right)$ and carbon monoxide (CO), gases typically present in diesel engine exhaust after SCR process. Sensors prepared of mixed phases of $\mathrm{V}_{2} \mathrm{O}_{5}$ and $\mathrm{V}_{7} \mathrm{O}_{16}$ could clearly follow ppm-range changes of $\mathrm{NH}_{3}$ despite of different levels of $\mathrm{NO}_{\mathrm{x}}$ interferences in the background, and also the detection limit of such sensing materials to $\mathrm{CO}(\approx 50 \mathrm{ppm})$ was clearly higher than to $\mathrm{NH}_{3}(\approx 40 \mathrm{ppb})[16]$. However, when the film is composed almost solely of one phase, the sensitivity is decreased. On the other hand, it was also found that the pure $\mathrm{V}_{2} \mathrm{O}_{5}$ phase film is more electrically and thermally stable than the films with more mixed phase structures [16]. The reason for this is most probably the higher amount of oxygen vacancies due to the presence of certain amount of $\mathrm{V}_{7} \mathrm{O}_{16}$ in the films, which then causes instability at higher temperatures. When the film is composed of pure $\mathrm{V}_{2} \mathrm{O}_{5}$ phase, the valence states of the film contain almost totally only $\mathrm{V}^{5+}$ ions. But when an increasing amount of $\mathrm{V}^{4+}$ ions is introduced to the structure with the $\mathrm{V}_{7} \mathrm{O}_{16}$ symmetry, the amount of oxygen vacancies is increased, causing an 
increase in the gas response, but on the other a decrease in the stability at higher temperatures. Also, it was shown in Ref. [11] that the $\mathrm{V}_{7} \mathrm{O}_{16}$ phase, at certain conditions, behaves like a $p$-type semiconductor, while the pure $\mathrm{V}_{2} \mathrm{O}_{5}$ is known as $n$-type semiconductor. This causes the existence of $p$ - $n$ junction grain boundaries in the films where a suitable amount of both phases are mixed together. The existence of the $p$ - $n$ junctions leads to higher baseline resistance, which also can lead to higher gas responses. When the $p$-type $\mathrm{V}_{7} \mathrm{O}_{16}$ is the dominant phase, the resistance level is again lower, which causes also a decrease in the gas response.

The films deposited on silicon have proven to be extremely sensitive to ammonia down to $\approx 40$ ppb concentration, and also to large extent, selective to ammonia when compared to nitric oxide NO up to $20 \mathrm{ppm}$ and carbon monoxide $\mathrm{CO}$ up to $50 \mathrm{ppm}$ [16]. These are very important properties needed in gas sensors controlling the selective catalytic reduction (SCR) process used in diesel truck engines. In the process, urea, which forms ammonia, is used to reduce the produced toxic NO/ $\mathrm{NO}_{2}$ gas in the catalytic converter of the truck exhaust system to harmless nitrogen and water [26]. It has been suggested elsewhere, that layered, more open framework crystal structures, e.g. hexagonal $\mathrm{WO}_{3}$, are very suitable for detection of ammonia gas, the reason being the reaction of lattice oxygen of the metal oxide with the measured gas, and easy mechanisms for adjusting the unstoichiometric metal to oxygen ratio $[27,28]$. As was already mentioned in the introduction, also $\mathrm{V}_{2} \mathrm{O}_{5}$ and $\mathrm{V}_{7} \mathrm{O}_{16}$ are formed of layered structures and thus should be considered as highly potential ammonia sensing materials.

An example of a gas response with ammonia gas concentrations at ppb-levels is shown in Fig 7. The measurement temperature was $350{ }^{\circ} \mathrm{C}$ and the gas injection and dwell time was 2 hours. It can be seen that the sensor shows a clear response already at $200 \mathrm{ppb}$ level of ammonia. However, there is a small drift present in the resistance baseline and also the response time is not very fast. Yet, types of vanadium oxide thin-film structures have been proven to be a promising candidate as a material for ammonia gas sensors [16]. 


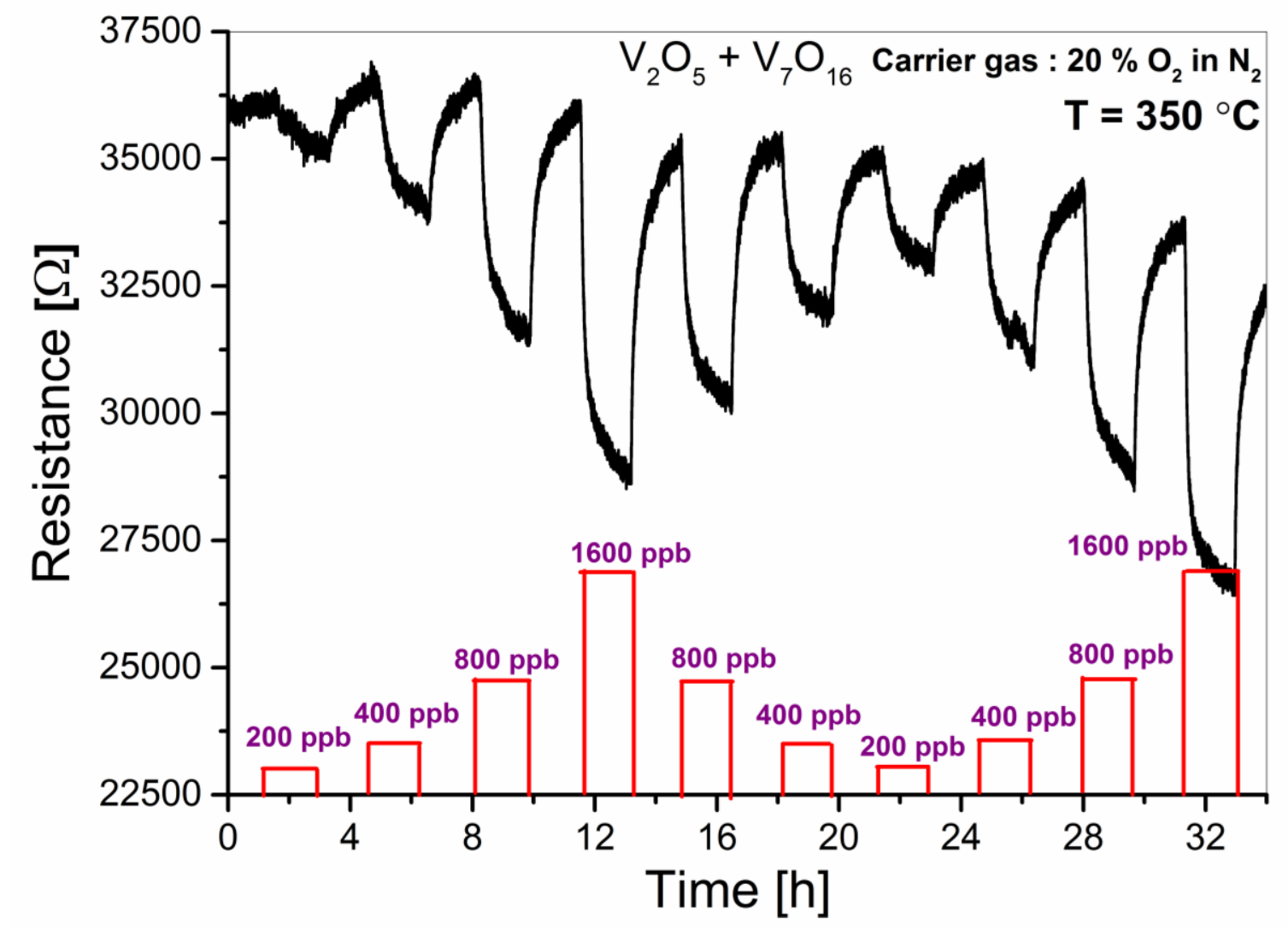

Figure 7. The sensor signal, measured as the resistance, of the mixed phase, $\mathrm{V}_{2} \mathrm{O}_{5}+\mathrm{V}_{7} \mathrm{O}_{16}$, during exposure to $\mathrm{NH}_{3}$ at ppb-level concentrations. The measurement was performed at $\mathrm{T}=350{ }^{\circ} \mathrm{C}$ and with $20 \%$ of $\mathrm{O}_{2}$ in $\mathrm{N}_{2}$ as a carrier gas.

\section{Conclusions}

A thorough structural study of pulsed laser deposited vanadium oxide thin films was performed. Xray diffraction and Raman spectroscopy results showed the co-existence of orthorombic $\mathrm{V}_{2} \mathrm{O}_{5}$ phase, and a phase usually seen in vanadium oxide nanotubes $\left(\mathrm{VO}_{\mathrm{x}}-\mathrm{NTs}\right)$. Rietveld refinement performed on the XRD data confirmed two crystal structures of orthorhombic $\mathrm{V}_{2} \mathrm{O}_{5}$ phase and triclinic $\mathrm{V}_{7} \mathrm{O}_{16}$ phase. Triclinic $\mathrm{V}_{7} \mathrm{O}_{16}$ phase is previously only found in layered wall structure of $\mathrm{VO}_{\mathrm{x}}-\mathrm{NTs}$ with a chemical amine between the $\mathrm{V}_{7} \mathrm{O}_{16}$ phase twin-plane layers. The transmission electron microscopy studies supported XRD and Raman spectroscopy results by proving that all the thin films had polycrystalline structure, and also fiber or tubular-like nanostructures were found, especially in the film compositions containing the $\mathrm{V}_{7} \mathrm{O}_{16}$ phase. When the film was composed of 
equal mixture of both phases $\mathrm{V}_{2} \mathrm{O}_{5}$ and $\mathrm{V}_{7} \mathrm{O}_{16}$, the microstructure was very porous and the surface especially rough. The measured surface potential values showed the clear difference in the work functions of the two phases of about $\approx 40 \mathrm{meV}$. The films were also tested as a possible sensing material for ammonia gas, and response to $\mathrm{NH}_{3}$ was seen already at ppb-levels of gas concentration.

\section{Acknowledgements}

Financial support of Finnish Funding Agency for Innovations - TEKES project CHEMPACK (no. 1427/31/2010) is acknowledged. The assistance of Center of Microscopy and Nanotechnology of University of Oulu is acknowledged. The assistance of Biocenter Oulu of University of Oulu is acknowledged. J. Huotari acknowledges the Tauno Tönning foundation, Henry Ford foundation, Ulla Tuominen foundation, and Riitta and Jorma J. Takanen foundation for financial support, as well. R. Bjorklund and J. Eriksson thank the Swedish Research Council for support.

\section{References}

[1] F. Beteille, J. Livage, Optical switching in $\mathrm{VO}_{2}$ thin films, J. Sol-Gel Sci. Technol. 13 (1998) 915-921.

[2] V. Modafferi, S. Trocino, A. Donato, G. Panzera, G. Neri, Electrospun $\mathrm{V}_{2} \mathrm{O}_{5}$ composite fibers: synthesis, characterization and ammonia sensing properties, Thin Solid Films 548 (2013) 689-694.

[3] Z. Huang, Z. Zhu, Z. Liu, Combined effect of $\mathrm{H}_{2} \mathrm{O}$ and $\mathrm{SO}_{2}$ on $\mathrm{V}_{2} \mathrm{O}_{5} / \mathrm{AC}$ catalysts for NO reduction with ammonia at lower temperatures, Appl. Catal. B 39 (2002) 361-368.

[4] F. Krumeich, H.-J. Muhr, M. Niederberger, F. Bieri, B. Schnyder, R. Nesper, Morphology and topochemical reactions of novel vanadium oxide nanotubes, J. Am. Chem. Soc. 121 (1999) 8324 - 8331. 
[5] M. Wörle, F. Krumeich, F. Bieri, H-J. Muhr, R. Nesper, Flexible $\mathrm{V}_{7} \mathrm{O}_{16}$ layers as the common structural element of vanadium oxide nanotubes and a new crystalline vanadate, Z. Anorg. Allg. Chem., 628 (2002) 2778-2784.

[6] M. Roppolo, C.B. Jacobs, S. Upreti, N.A. Chernova, M.S. Whittingham, Synthesis and characterization of layered and scrolled amine-templated vanadium oxides, J. Mater. Sci. 43 (2008) 4742-4748.

[7] M. Yu, X. Liu, Y. Wang, Y. Zheng, J. Zhang, M. Li, W. Lan, Q. Su, Gas sensing properties of p-type semiconducting vanadium oxide nanotubes, Appl. Surf. Sci. 258 (2012) 9554-9558.

[8] S. Nordlinder, A. Augustsson, T. Schmitt, J. Guo, L.C. Duda, J. Nordgren, T. Gustafsson, K. Edström, Redox behavior of vanadium oxide nanotubes as studied by x-ray photoelectron spectroscopy and soft x-ray absorption spectroscopy, Chem. Mater. 15 (2003) $3227-3232$.

[9] Y. Wang, K. Takahashi, K. Lee, G. Cao, Nanostructured vanadium oxide electrodes for enhanced lithium-ion intercalation, Adv. Funct. Mater. 16 (2006) 1133-1144.

[10] S. Surnev, M.G. Ramsey, F.P. Netzer, Vanadium oxide surface studies, Prog. Surf. Sci (2003) 117-165.

[11] J. Huotari, J. Lappalainen, J. Puustinen, A. Lloyd Spetz, Gas sensing properties of pulsed laser deposited vanadium oxide thin films with various crystal structures, Sens. Actuators B: Chem 187 (2013) 386-394.

[12] P.Y. Zavalij, M.S. Whittingham, Structural chemistry of vanadium oxide with open frameworks, Acta Cryst. B55 (1999) 627-663. 
[13] P.J. Fillingham, Domain structure and twinning in crystal of vanadium dioxide, J. Appl. Phys. 38 (1967) 4823.

[14] D. H. Kim, H. S. Kwok, Pulsed laser deposition of $\mathrm{VO}_{2}$ thin films, Appl. Phys. Lett. 65 (1994) 3188 - 3190.

[15] C. V. Ramana, R. J. Smith, O. M. Hussain, C. M. Julien, Growth and surface characterization of $\mathrm{V}_{2} \mathrm{O}_{5}$ thin films made by pulsed-laser deposition, J. Vac. Sci. Technol. A 22 (2004) 2453-2458.

[16] J. Huotari, R. Bjorklund, J. Lappalainen, A. Lloyd Spetz, Pulsed laser deposited nanostructured vanadium oxide thin films characterized as ammonia sensors, Sens. Actuator B: Chem. 217 (2015) 22-29.

[17] K. Momma, F. Izumi, VESTA 3 for three-dimensional visualization of crystal, volumetric and morphology data, J. Appl. Crystallogr. 44 (2011) 1272-1276.

[18] I. Horcas, R. Fernández, J.M. Gómez-Rodríguez, J. Colchero, J. Gómez-Herrero, A.M. Baro, WSXM: A software for scanning probe microscopy and a tool for nanotechnology, Rev. Sci. Instrum. 78 (2007) 013705.

[19] C. Julien, E. Haro-Poniatowski, M.A. Camacho-López, L. Escobar-Alarcón, J. JímenezJarquín, Growth of $\mathrm{V}_{2} \mathrm{O}_{5}$ thin films by pulsed laser deposition and their applications in lithium microbatteries, Mater. Sci. Eng. B 65 (1999) 170-176.

[20] X. Liu, C. Huang, J. Qiu, Y. Wang, The effect of thermal annealing and laser irradiation on the microstructure of vanadium oxide nanotubes, Appl. Surf. Sci. 253 (2006) 27472751.

[21] A.G. Souza Filho, O.P. Ferreira, E.J.G. Santos, J. Mendes Filho, O.L. Alves, Raman spectra in vanadate nanotubes revisited, Nano Lett. 4 (2004) 2099-2104. 
[22] S. Laubach, P.C. Schmidt, A. Thißen, F.J. Fernandez-Madrigal, Q-H. Wu, W. Jaegermann, M. Klemm, S. Horn, Theoretical and experimental determination of the electronic structure of $\mathrm{V}_{2} \mathrm{O}_{5}$, reduced $\mathrm{V}_{2} \mathrm{O}_{5-\mathrm{x}}$ and sodium intercalated $\mathrm{NaV}_{2} \mathrm{O}_{5}$, Phys. Chem. Chem. Phys. 9 (2007) 2564-2576.

[23] L.B. McCusker, R.B. Von Dreele, D.E. Cox, D. Louer, P. Scardie, Rietveld refinement guidelines, J. Appl. Cryst. 32 (1999) 36-50.

[24] R. Enjalbert, J. Galy, A refinement of the structure of $\mathrm{V}_{2} \mathrm{O}_{5}$, Acta Crystallogr. C42 (1986) 1467-1469.

[25] A. Perez-Pacheco, D. R. Acosta-Najarro, R. Castaneda-Guzman, H. Cruz-Manjarrez, L. Rodriguez-Fernandez, J. C Pineda-Santamaria, M. Aguilar-Franco, Evidence of the semiconductor-metal transition in $\mathrm{V}_{2} \mathrm{O}_{5}$ thin films by the pulsed laser photoacoustic method, J. Appl. Phys. 113 (2013) 184307.

[26] H. Wingbrant, H. Svenningstorp, P. Salomonsson, D. Kubinski, J.H. Visser, M. Löfdahl, A. Lloyd Spetz, Using a misic-FET sensor for detecting $\mathrm{NH}_{3}$ in SCR systems, IEEE Sens. J. 5 (2005) 1099-1105.

[27] C. Balazsi, L. Wang, E. Ozkan Zayim, I. Miklos Szilagyi, K. Sedlackov, J. Pfeifer, A. L. Toth, P.I. Gouma, Nanosize hexagonal tungsten oxide for gas sensing applications, J. Eur. Ceram. Soc. 28 (2008) 913-917.

[28] L. Wang, J. Pfeifer, C. Balázsi, P.I. Gouma, Synthesis and sensing properties to $\mathrm{NH}_{3}$ of hexagonal $\mathrm{WO}_{3}$ metastable nanopowders, Mater. Manuf. Processes 22 (2007) 773-776. 